\title{
Extensive progressive multifocal leukoencephalopathy as the first manifestation of AIDS
}

\author{
Lénio Parreira do Couto ${ }^{[1]}$, Vanessa Barcelos ${ }^{[1]}$ and André Goulart ${ }^{[1]}$
}

[1]. Hospital de Santo Espírito da Ilha Terceira, Serviço de Medicina Interna, Angra do Heroísmo, Portugal.

Progressive multifocal leukoencephalopathy (PML) is an AIDSdefining illness caused by John Cunningham virus (JCV). The most common clinical findings are speech and language disturbances, motor weakness, gait abnormalities, and incoordination. Clinical and radiological features sustain the diagnosis along with detection of JCV in the cerebrospinal fluid (CSF). The majority of HIV patients diagnosed with PML have CD4+ counts $<200$ cells $/ \mu \mathrm{L}^{1}$.

Brain magnetic resonance imaging (MRI) is the mainstay of radiological evaluation, showing areas of hyperintensity on T2weighted and fluid-attenuated inversion recovery (FLAIR) images and hypointensity on T1-weighted images. Multiple subcortical lesions are often present in the basal ganglia or thalamus, where myelinated fibers reside ${ }^{2}$.

A 59-year-old man was admitted for cognitive deterioration, gait difficulty, and urinary incontinence for 3 weeks. Neurological examination revealed severe language and executive function impairments. Infection with HIV-1 was diagnosed 1 year ago, but he had not started antiretroviral therapy, and he was asymptomatic. CD4+ assessment showed 422 cells $/ \mathrm{mm}^{3}$. Brain MRI showed evidence of bilateral cortico-subcortical frontal lesions and in the left striatocapsular region, hyperintensity on T2 and FLAIR images with corresponding hypointensity in T1 images, and restriction in diffusion-weighted images (Figure 1). JCV was identified in the $\mathrm{CSF}$, and the diagnosis of PML was made.

This case illustrates that PML lesions can be extensive and debilitating, even in patients with a high CD4+ count.

\section{ORCID}

Lénio Parreira do Couto: 0000-0002-2003-2806

Vanessa Barcelos: 0000-0003-0867-2576

André Goulart: 0000-0001-6869-9565

Corresponding author: Dr. Lénio Parreira do Couto.

e-mail: lenio.f.couto@azores.gov.pt

(D) http://orcid.org/0000-0002-2003-2806

Received 8 February 2021

Accepted 26 February 2021

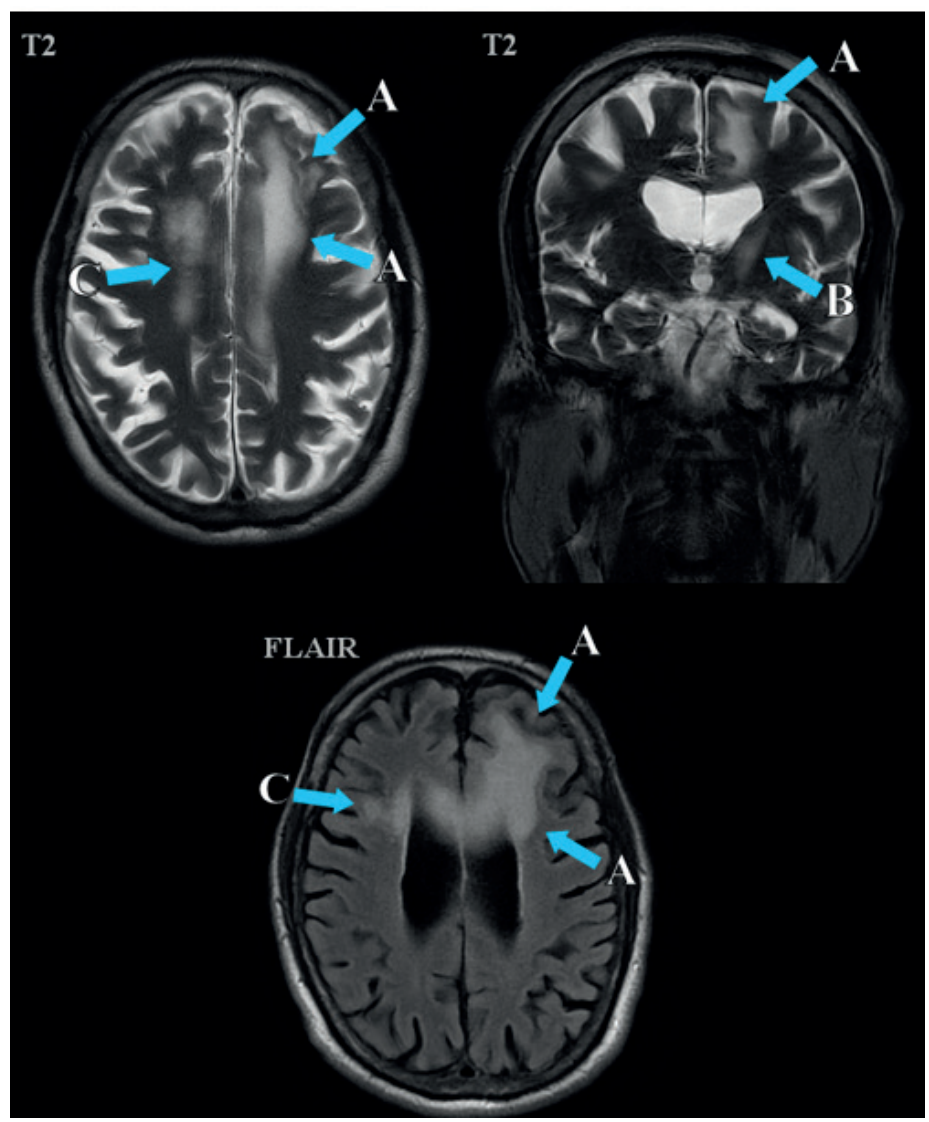

FIGURE 1: Brain MRI showing an extensive hyperintense lesion on T2 and FLAIR images in the left frontal parasagittal cortico-subcortical (A) and striatocapsular regions (B) and right frontal subcortical area (C).

\section{AUTHORS' CONTRIBUTION}

LPC: Data collecting and analysis, Scientific review, Clinical handling, Paper writing and submition; VB: Clinical handling, Critical revision; AG: Scientific review, Critical revision.

\section{CONFLICT OF INTEREST}

The authors declare that there is no conflict of interest. 


\section{FINANCIAL SUPPORT}

No funding to declare.

\section{REFERENCES}

1. Iannetta M, Ciardi MR, Zingaropoli MA, D'Abramo A, Oliva A, Mastroianni CM, et al. HIV-associated progressive multifocal leukoencephalopathy: current perspectives. Neurobehav HIV Med. 2016;7:43-52.

2. TanCS,KoralnikIJ.Beyond progressivemultifocal leukoencephalopathy: expanded pathogenesis of JC virus infection in the central nervous system. Lancet Neurol. 2010;9(4):425-37. 